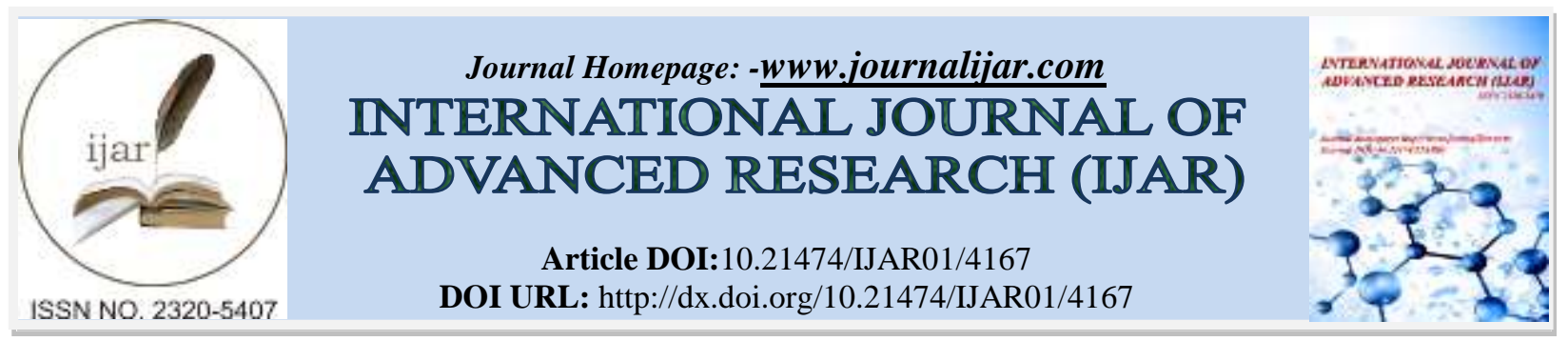

RESEARCH ARTICLE

\title{
TEMPOMANDIBULAR JOINT EVALUATION IN RHEUMATOID ARTHRITIS PATIENTS USING MAGNETIC RESONANCE IMAGING.
}

\section{Ola Mohamed Rehan MSc ${ }^{1}$, Hoda Abdel Kader Saleh $\mathrm{PhD}^{2}$, Hala Ahmed Raffat $\mathrm{PhD}^{3}$, Dr. Ayman Ismail Kamel $\mathrm{PhD}^{4}$ and Noha Saleh Abu Taleb (PhD) ${ }^{5}$. \\ 1. Assistant Lecturer of Oral and Maxillofacial Radiology, Faculty of Oral and Dental Medicine, Cairo University. \\ 2. Professor of Oral and Maxillofacial Radiology, Faculty of Oral and Dental Medicine, Cairo University. \\ 3. Professor of Rheumatology and Rehabilitation, Faculty of Medicine, Cairo University. \\ 4. Professor of Radiology, Faculty of Medicine, Cairo University \\ 5. Assoc. Professor of Oral and Maxillofacial Radiology, Faculty of Oral and Dental Medicine, Cairo University.}

\section{Manuscript Info}

Manuscript History

Received: 13 March 2017

Final Accepted: 11 April 2017

Published: May 2017

\section{Key words:-}

Magnetic resonance imaging;

Temporomandibular joint; Rheumatoid arthritis.

\section{Abstract}

Objective: To evaluate the temporomandibular joint abnormalities in the patients with rheumatoid arthritis using magnetic resonance imaging.

Methods: Twenty eight subjects (56 TMJs). They were divided into two groups; (RA) group which comprised 14 RA patients and control group which comprised 14 volunteers. Magnetic resonance imaging was performed for each patient in closed and open mouth positions. Each joint was examined for soft tissue and osseous abnormalities.

Results: The RA group showed statistically significant higher prevalence of erosion $(P=0.007)$, flattening $(P=0.006)$, subchondral cyst $(P=0.019)$, and sclerosis $(P=0.018)$ than the control group. On the other hand, there was no statistically significant difference between the soft tissue findings of the TMJs in both the control group and RA group. Furthermore, there was no correlation between the disease duration and MRI findings

Conclusion: Temporomandibular joint osseous and soft tissue abnormalities are not uncommon in the rheumatoid arthritis patients thus, Temporomandibular joint imaging is recommended for rheumatoid arthritis patients.

Copy Right, IJAR, 2016,. All rights reserved.

\section{Introduction:-}

Rheumatoid arthritis (RA) is a systemic chronic inflammatory disease with unidentified aetiology that affects the joints. Temporomandibular joint (TMJ) involvement in RA patients is a common condition (Hiz et al., 2012).

The incidence of TMJ involvement ranges from 5 to $86 \%$ (Syrjanen, 1985). The involvement of the TMJ may be associated with soft tissue abnormalities such as disc displacement and bone abnormalities such as erosion, flattening, osteophytes, sclerosis, deformity (Uchiyama et al., 2013).

A variety of modalities can be used to image the TMJ. This includes conventional radiographs, ultrasound, computed tomography (CT), and magnetic resonance imaging (MRI) (Bag et al., 2014). 
MRI has great advantages over the previous techniques in its ability to illustrate the soft tissue changes of the TMJ besides the detection of the osseous abnormalities (Alkhader et al., 2010). Thus, the aim of this study is to evaluate the TMJ abnormalities in RA patients using MRI.

\section{Patients and Methods:-}

The current study design was discussed and approved by the Institutional-Review-Board, Faculty of Oral and Dental Medicine, Cairo University. A written informed consent was obtained from all the patients sharing in the study.

Twenty eight subjects were included in the study. They were divided in two groups; RA group which comprised 14 RA patients and Control group which comprised14 healthy subjects. The RA group was selected from the outpatient clinic of Rheumatology and Rehabilitation Department, Faculty of Medicine, Cairo University. The control group was selected from the outpatient clinic of the Oral and Maxillofacial Radiology Department, Faculty of Oral and Dental Medicine, Cairo University. Inclusion criteria for the RA group included: RA disease duration more than 2 years. Exclusion criteria included: presence of any systemic condition affecting TMJ other than rheumatoid arthritis, presence of any local factor affecting TMJ function, facial nerve paralysis, trigeminal neuralgia, patients who underwent TMJ injection in the last six months and pregnant females.

MRI examination was performed at the Radiology Department, Faculty of Medicine, Cairo University using $1.5 \mathrm{~T}$ superconductive magnet. A surface coil of $17 \mathrm{~cm}$ external diameter and $14 \mathrm{~cm}$ internal diameter was used.

Corrected T1WIs, Fat suppressed T2WIs, and PDWIs sagittal images of the TMJ were obtained. The Fat suppressed T2WIs and PDWIs were acquired in closed and open mouth positions. T1WI parameters (spin echo 'SE', TR: 435 ms, TE: 14 ms, NEX: 3, FOV: 150 mm, Image matrix: 240× 192, Slice thickness: $2.5 \mathrm{~mm}$, Interslice gap: 0.25 mm, Flip angle: $90^{\circ}$ Acquisition time: 4 minutes and 14 seconds).

PDWI parameters (turbo spin echo (TSE), TR: 1.5 s, TE: 30 ms, NEX: 3, FOV: 150 mm, Image matrix: 240× 192, Slice thickness: $2.5 \mathrm{~mm}$, Interslice gap: $0.25 \mathrm{~mm}$, Flip angle: 90 ${ }^{\circ}$, Acquisition time: 4 minutes and 51 seconds). Sagittal fat suppressed-T2WIparameters (turbo spin echo (TSE), TR: 2.5 s, TE: 90 ms, NEX: 6, FOV: 150 mm, Image matrix: $152 \times 114$, Slice thickness: $2.5 \mathrm{~mm}$, Interslice gap: $0.25 \mathrm{~mm}$, Flip angle: $90^{\circ}$, Acquisition time: 1 minute and 45 seconds).

\section{Image Analysis:-}

MR images were examined for the presence/absence of any osseous changes. These changes were: Erosion (loss of continuity of the articular surface); Flattening (loss of convexity of the condyle); Osteophyte formation (low signal intensity outgrowth); Condylar deformity (any major change in the morphological shape of the condyle); Subchondral cyst (well-circumscribed low signal intensity area on T1WI with high signal intensity on T2WI); Sclerosis (low signal intensity area in MRI-T1WIs and T2WIs); Condylar irregularities ( irregular surface or irregular and coarse resorptive changes of the cortical surface)

As well, The MRI TMJ images were examined for the presence/absence of soft tissues changes. These changes were: Alteration in the normal disc shape and position (Alteration in the normal biconcave disc shape may vary from enlargement of the posterior band to bilinear or convex disc outline. In the closed mouth position, the normal disc is positioned with the posterior band directly superior to the condylar head; whereas, in the open position, the thin intermediate part remains the articulating surface of the disc between the condyle and articular eminence. Alteration in the normal disc position revealed as disc displacement with or without reduction). Joint effusion (an area of high signal intensity in the upper and /or lower joint spaces on T2WIs); Bone marrow odema (an ill-defined area of increased signal intensity in bone marrow that is seen on water-sensitive MRI sequences "T2WIs and fat suppression T2WIs").

The images were analyzed by three radiologists with varying experiences and a calibration session was performed to set the diagnostic criteria for the TMJ assessment. Image interpretation of each examination was performed without previous knowledge about the group to which the subject is included or the results of the other examiners. Moreover, the presence or absence of each soft tissue/osseous abnormality was evaluated independently by the observers. A consensus judgment of the imaging findings was based upon the majority opinion of the observers. 


\section{Statistical Analysis:-}

The comparison between the two groups with qualitative data were done by using Chi-square test $\left(x^{2}\right)$ and/or Fisher exact test that was used instead of Chi-square test when the expected count in any cell was found less than 5. Comparison between two independent groups regarding quantitative data with parametric distribution was done by using Independent t-test.

\section{Results:-}

The RA group showed statistically significant higher prevalence of erosion, flattening, subchondral cyst, and sclerosis than the control group (Table 1). On the other hand, there was no statistically significant difference between the soft tissue findings of the TMJs in both the control group and RA group (Table 2). The TMJ abnormalities are illustrated in (Fig 1 to7).

Table 1:- The frequency, percentages and P-value of comparison between the osseous changes in the two studied groups using MRI

\begin{tabular}{|l|l|l|l|l|l|}
\hline \multirow{2}{*}{ MRI } & \multicolumn{2}{l|}{$\begin{array}{l}\text { Control group } \\
(\mathbf{N = 2 8})\end{array}$} & $\begin{array}{l}\text { RA } \\
\text { (N=28) }\end{array}$ & \multirow{2}{*}{-value } \\
\cline { 2 - 5 } & Frequency & \% & Frequency & \% & \\
\hline Erosion & 16 & 57.1 & 25 & 89.3 & $0.07^{*}$ \\
\hline Flattening & 12 & 42.9 & 22 & 78.6 & $0.006^{*}$ \\
\hline Osteophyte formation & 9 & 32.1 & 6 & 21.4 & 0.365 \\
\hline Condylar deformity & 0 & 0 & 3 & 10.7 & 0.075 \\
\hline Subchondral cyst & 0 & 0 & 5 & 17.9 & $0.019^{*}$ \\
\hline Sclerosis & 4 & 14.3 & 12 & 42.9 & $0.018^{*}$ \\
\hline Condylar irregularities & 1 & 3.6 & 4 & 14.3 & 0.160 \\
\hline
\end{tabular}

*: Significant at $P \leq 0.05$

Table 2:-The frequencies, percentages, and P-values of comparison between the MRI soft tissue changes in the two studied groups

\begin{tabular}{|l|l|l|l|l|l|}
\hline \multirow{2}{*}{ MRI } & $\begin{array}{l}\text { Control group } \\
(\mathbf{N = 2 8})\end{array}$ & \multicolumn{2}{l|}{$\begin{array}{l}\text { RA patients } \\
(\mathbf{N}=28)\end{array}$} & \multirow{2}{*}{-value } \\
\cline { 2 - 6 } & Frequency & $\mathbf{\%}$ & Frequency & \% & \\
\hline Disc shape change & 0 & 0 & 0 & 0 & NA* $^{*}$ \\
\hline${ }^{*}$ ADDR & 4 & 14.3 & 2 & 7.1 & 0.388 \\
\hline e.eADDWR & 1 & 3.6 & 0 & 0 & 0.313 \\
\hline Joint effusion & 4 & 14.3 & 10 & 35.7 & 0.064 \\
\hline Bone marrow odema & 1 & 3.6 & 2 & 7.1 & 0.553 \\
\hline
\end{tabular}

*Not Available

"Anterior disc displacement with reduction

"Anterior disc displacement without reduction 


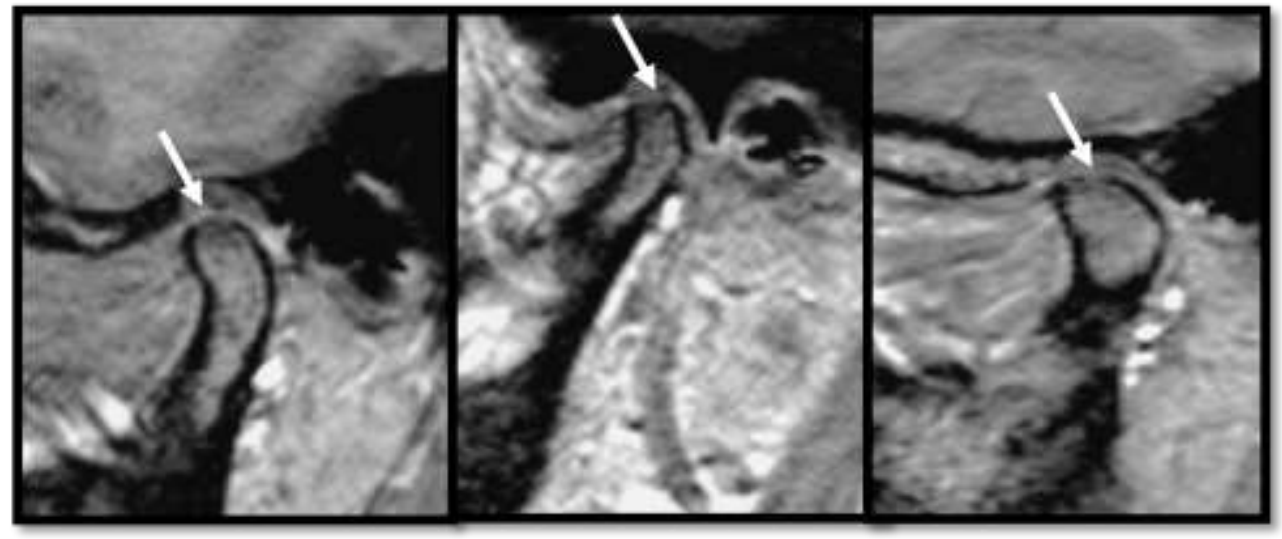

Fig 1:- Corrected sagittal MRI-T1WIs of RA patieits showing condylar erosions which appear as loss of cortical contin'lity (arrows).
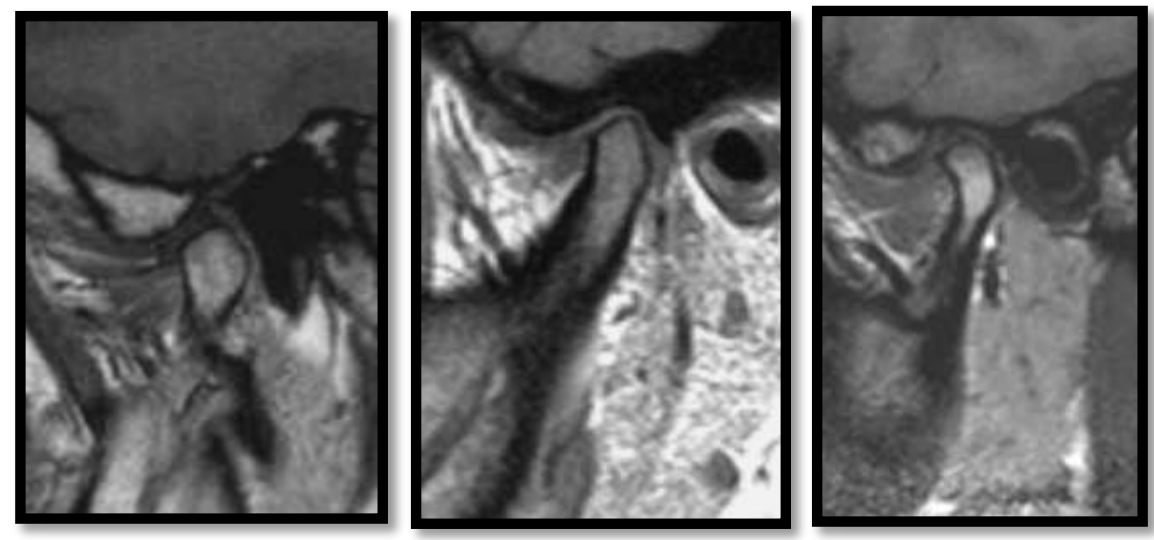

Fig 2:-Corrected sagittal MRI-T1WIs of RA patients showing flattening of the superior surface of the condyle.
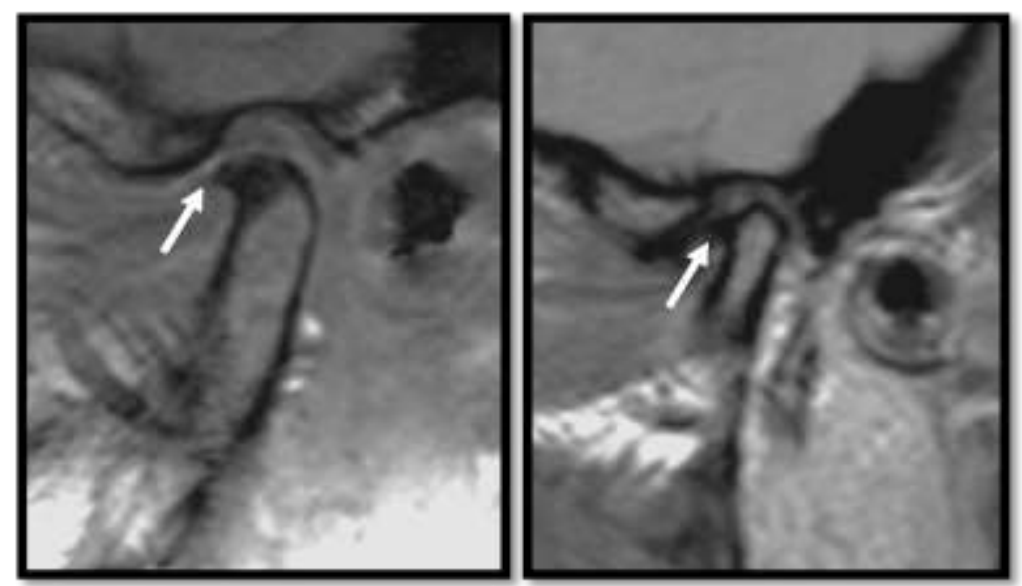

Fig 3:-Corrected sagittal MRI-T1WIs of RA patients showing osteophyte formation of different sizes at the anterior surface of the condyle (arrows). 


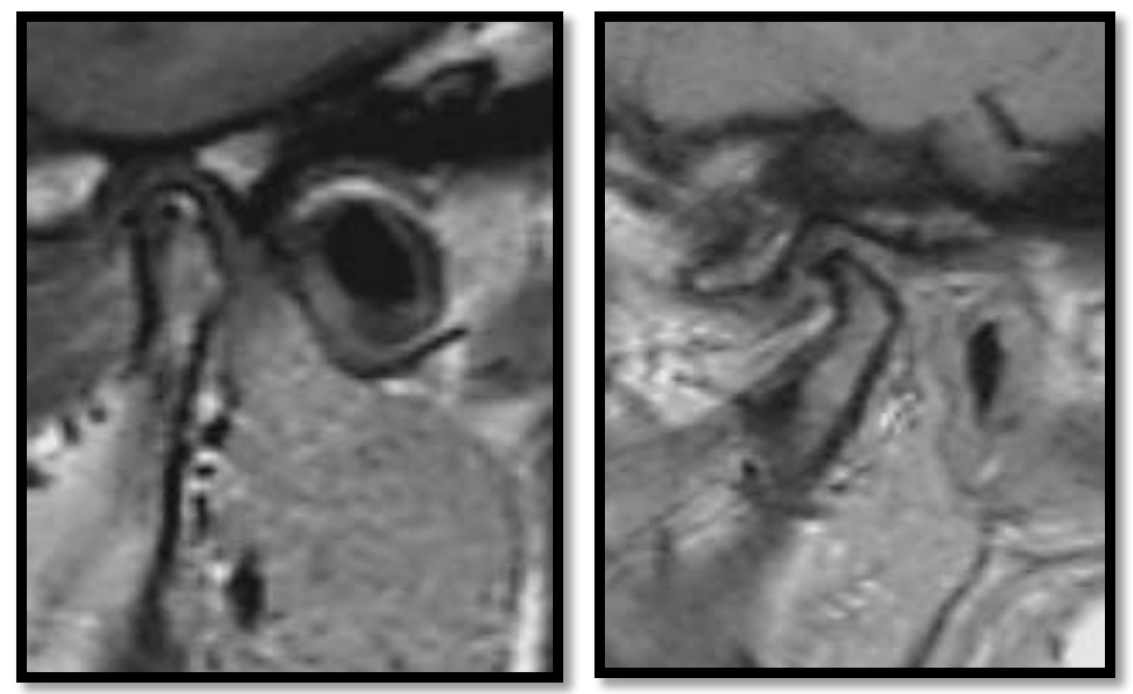

Fig 4:- Corrected sagittal MRI-T1WIs of RA patients showing condylar deformity.

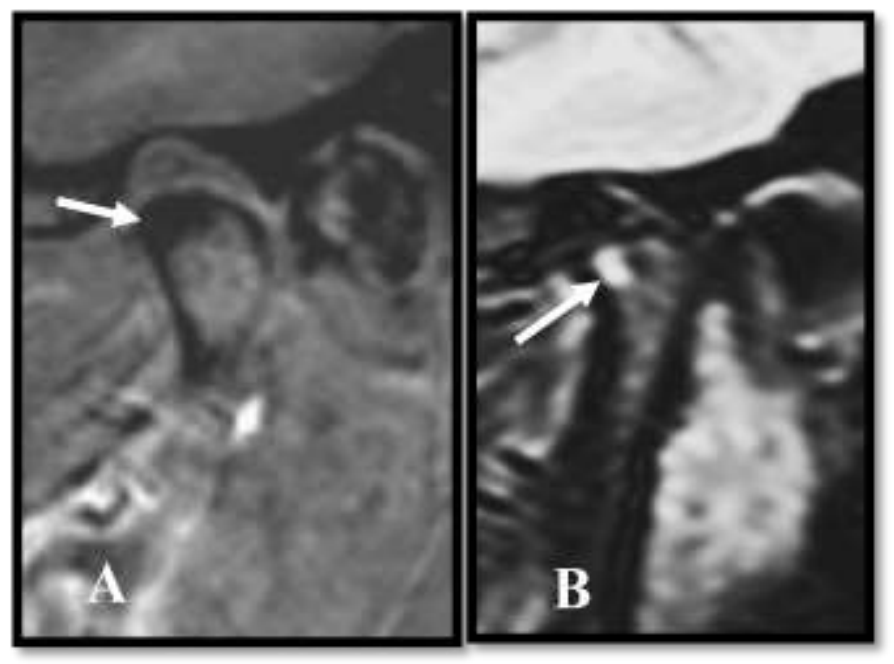

Fig 5:- Corrected sagittal MRI showing subchondral cyst. A) T1WI showing low signal intensity area (arrow). B) Fat suppressed-T2WI was examined to confirm the T1WI finding and it showed high signal intensity of the same area (arrow). 

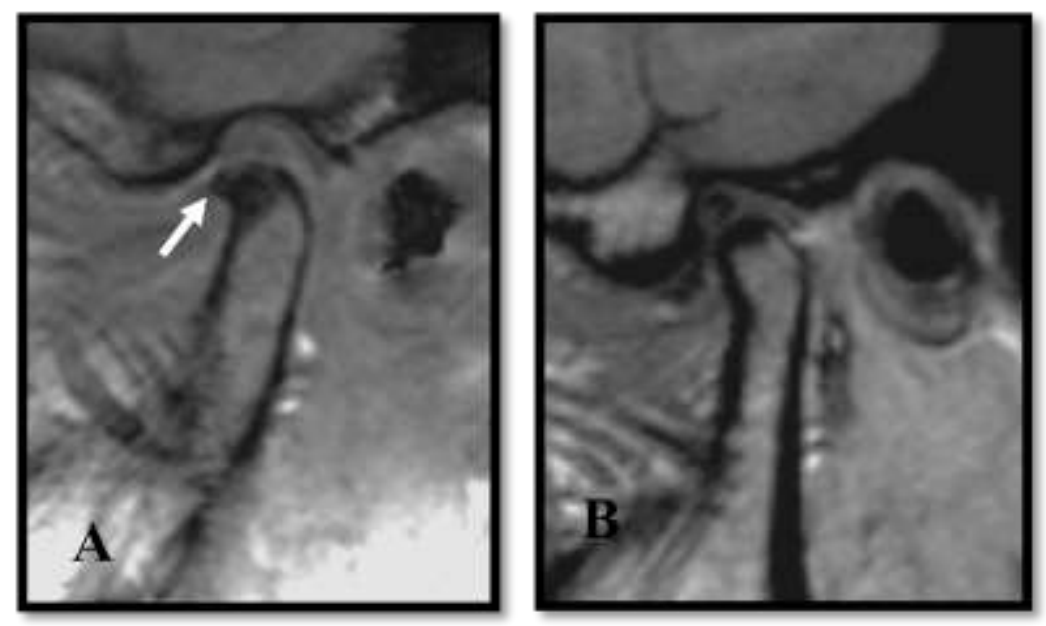

Fig6:- Corrected sagittal MRI-T1WIs of RA patients showing subchondral sclerosis of the condyle. Note the condylar deformity and osteophyte in(A) (arrow).

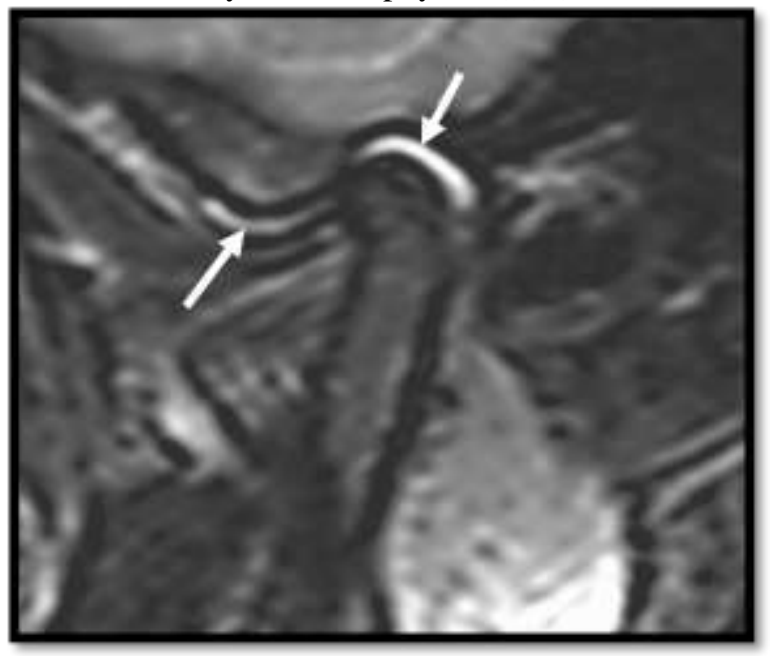

Fig 7:-Corrected fat suppressed-sagittal MRI-T2WI in the closed mouth position showing joint effusion as a high signal intensity (arrows) of the upper and lower joint spaces.

\section{Discussion:-}

Rheumatoid arthritis (RA) is a chronic inflammatory systemic disease that involves the joints dominantly and in symmetrical manners. It is characterized by persistent joint synovial tissue inflammation. Over time, bone erosion, destruction of cartilage, and complete loss of joint integrity can occur. TMJ is commonly involved in the RA patients with frequency varying between 2 to 86\% (Rindfleisch and Muller 2005; Yilmaz et al. 2012). Thus, the aim of this study is to assess the TMJ abnormalities in RA patients using MRI

The MRI examination was acquired in both closed and open mouth positions to assess the disc position. Hence, this was performed in the afternoon to avoid morning stiffness of the joints that may occur in some RA patients. The same time interval was considered in the control group for standardization.

Owing to the small size of the TMJ, bilateral surface coils were used during the examination to increase the signal to noise ratio (SNR) and improve the resolution (Weishaupt et al., 2006).

As said by (Aiken et al., 2012) the standard non-contrast MRI protocol for TMJ examination includes conventional T1WI, T2WI and PDWI sequences. However, (Grande et al., 2014) reported that bone marrow abnormalities are 
better seen in fat suppressed T2WIs. Therefore, in the current study the standard sequences were performed with fat suppression of the T2WIs.

The TMJ images of all MRI sequences were examined for the presence/absence of any osseous changes. These changes were erosion, flattening, osteophyte formation, condylar deformity, sclerosis, subchondral cyst, and condylar irregularities. These are the typical and most common radiographic osseous changes in the TMJ of RA patients (Helenius et al., 2006; Tsiklakis, 2010; Witulski et al,. 2014).

As stated by (Smith et al., 1992) and (Sommer et al., 2003) the synovial proliferation that occurs in RA can affect the joint disc. Also, joint effusion and bone marrow edema may occur in the active phase of the disease. Therefore, in the current study, the MR images were examined for the presence/absence of soft tissues changes including change in the disc shape and position, joint effusion or bone marrow edema.

The comparison between the MRI osseous findings in both groups revealed that the RA group had only statistically significant higher prevalence of erosion, flattening, subchondral cyst, and sclerosis than the control group.

The frequencies of erosion were $(57.1 \%$ and $89.3 \%)$ in the controls and the RA group respectively. This was near to (Kretapirom et al., 2013) who found that the frequency of erosion in MRI scans of RA patients was (96\%). However, lower frequencies were detected by (Yilmaz et al., 2012) and by (Witulski et al., 2014).

Flattening was detected in MRI images of both groups with frequencies $(42.9 \%$ and $78.6 \%)$ in the control and the RA groups respectively. Yet again, a lower value of flattening frequency was detected by (Uchima et al., 2013) in the studied RA patients.

Regarding the osteophytes that were detected in $(32.1 \%$ and $21.4 \%)$ of the controls and the RA group respectively. Whereas, (Helenius et al., 2006) found that the frequency was $(75 \%)$.

In the present study, condylar deformity was detected (7.1\%). Higher frequencies were reported in other studies by (Helenius et al., 2006) where condylar deformity was found in (31\%) of RA patients. Regarding the subchondral cyst, this was detected in images of the RA group only with frequencies (17.9\%). The cysts also revealed by (Helenius et al., 2006).

About sclerosis,this was detected in (14.3\% and $42.9 \%)$ of the controls and the RA group respectively. Regarding condylar irregularities, this was detected in $(3.6 \%$ and $14.3 \%)$ of the images of the controls and the RA group respectively.

The osseous changes occurring in RA are commonly due to immune cells such as T-cells, B-cells and macrophages as well as the cellular interaction among them through cytokines and cell surface molecules that play a pivotal role in the pathological processes of RA. The accumulation of inflammatory cells and the self-maintenance of inflammation in the synovial tissue stimulate induction and/or activation of osteoclasts that lead to cartilage and bone destruction. Moreover, the immune responses and inflammation in the synovial tissue cause synovial proliferation that leads to further bone destruction (Levin et al., 1996; Okochi et al., 2011).

Moreover, the higher frequency of occurrence of osteophyte in the RA group may be due to the trial of body to repair the joint by creating an osteophyte to stabilize and broaden the surface of the joint leading to better withstanding of the loading forces (Hussain et al., 2008).

For the subchondral cysts, there are two main postulated theories; the synovial intrusion theory and the bony contusion theory. The first theory suggested that the cysts could be secondary to pathology of the synovium extending into the bone owing to; the similarity of synovial fluid to the cystic fluid, abnormal articular cartilage over the cyst and displaced pieces of surface cartilage within the cyst. The second theory suggested that, the impact between opposing surfaces of bone, which have lost its protective cartilage results in microfractures and bone necrosis, after that, the synovial fluid intrudes the bone when the bone attempts to heal by osteoclastic resorption of the necrotic bone (Audrey et al., 2014). Further, the whole condylar head may be changed and destroyed due to severe erosive changes due to the RA (White and Pharoah, 2014). 
Despite that flattening and sclerosis are two pathologic processes, these may occur as a result of physiological remodelling to help the joint to withstand the extra forces applied on it (Schellhas et al., 1990; White and Pharoah, 2014). This may explain the occurrence of flattening and sclerosis in the both studied groups.

Regarding MRI soft tissue findings, no statistically significant differences were found between both groups. In the current study no change in the disc shape was detected in the two studied groups.

Regarding the disc position; ADDR was found in (14.3\% and 7.1\%) of the controls and RA group respectively; while, ADDWR was detected only in one volunteer (3.6\%). (Yilmaz et al., 2012) observed disc displacement $(6.8 \%$ and $10.7 \%$ ) in controls and RA patients respectively. Moreover, (Kretapirom et al., 2013) found that the ADDR and ADDWR occurred in RA patients. Later, a study published by (Witulski et al., 2014) revealed that the disc displacement occurred in both normal subjects and RA patients.

According to (Yilmaz et al., 2012) and (White and Pharoah, 2014) parafunctional habits may be present in RA patients which may lead to the disc displacement. However, one of our study limitations is that chewing habits were not inquired.

Regarding joint effusion, this occurred in (14.3\%and35.7\%) of both control and RA groups respectively. This was close to (Kretapirom et al., 2013) (33\%); however, lower frequency was detected by (Yilmaz et al., 2012) where joint effusion was observed in only (3.5\%) of RA patients.

As regards the bone marrow edema, this occurred in (3.6\% and 7.1\%) of control and RA groups respectively. As said by (Boj et al., 2007) the synovitis in the RA produces an exudate that accumulates in the joint spaces causing joint effusion and may reach the marrow spaces through the bony eroded areas leading to bone marrow edema. On the other hand, joint fluid may be seen in T2WIs of asymptomatic volunteers as stated by (Westesson and Brook, 1992) and (Arvidsson et al., 2010).

There was no correlation between the disease duration and MRI findings. This was inagreement with (Uchiyama et al., 2010) and (Witulski et al., 2014) who found no correlation between the disease duration and MRI findings.

\section{Conclusion:-}

TMJ osseous and soft tissue abnormalities are not uncommon in the RA patients thus, TMJ imaging is recommended for RA patients. Moreover, MRI is a valuable modality for TMJ assessment in RA.

\section{References:-}

1. Aiken A, Bouloux G, Hudgins P. (2012): MR Imaging of the Temporomandibular Joint. Magn Reson Imaging Clin N Am., 20: $397-412$.

2. Alkhader M, Ohbayashi N, Tetsumura A, Nakamura S, Okochi K, Momin MA, Kurabayashi T. (2010): Diagnostic performance of magnetic resonance imaging fordetecting osseous abnormalities of the temporomandibular jointand its correlation with cone beam computed tomography. Dentomaxillofac Radiol., 39: $270-276$.

3. Arvidsson LZ, Smith HJ, Flato B, Larheim TA. (2010): Temporomandibular Joint Findings in Adults with Longstanding Juvenile Idiopathic Arthritis: CT and MR Imaging Assessment. Radiology, 256 (1): 191 - 200.

4. Audrey HX, Bin Abd Razak HR, Andrew THC. (2014): The Truth Behind Subchondral Cysts in Osteoarthritis of the Knee. The Open Orthop J., 8: 7 - 10.

5. Bag AK, Gaddikeri S, Singhal A, Hardin S, Tran D, Medina JA, Curé JK. (2014): Imaging of the temporomandibular joint: An update. World J Radiol., 6 (8): 567 - 582.

6. Boj EJ, Huhmann IN, Schnabel BH, et al. (2007): Bone erosions and bone marrow edema as defined by magnetic resonance imaging reflect true bone marrow inflammation in rheumatoid arthritis. Arthritis \& Rheu., 56: (4): $1118-1124$.

7. Grande FD, Farahani SJ, Carrino JA, Chhabra A. (2014): Bone marrow lesions: A systematic diagnostic approach. Indian J Radiol Imaging, 24 (3): 279 -287.

8. Helenius LMJ, Tervahartiala P, Helenius I, Al-Sukhun J, Kivisaari L. (2006): Clinical, radiographic and MRI findings of the temporomandibular joint in patients with different rheumatic diseases. Int. J. Oral Maxillofac. Surg., 35: $983-989$. 
9. Hiz O, Ediza L, Ozkana Y, Borab A. (2012): Clinical and Magnetic Resonance Imaging Findings of the Temporomandibular Joint in Patients With Rheumatoid Arthritis. J Clin Med Res., 4 (5): 323 - 331.

10. Hussain AM, Packota G, Major PW, Flores-Mir C. (2008): Role of different imaging modalities in assessment of temporomandibular joint erosions and osteophytes: a systematic review. Dentomaxillofac Radiol., 37: 63 - 71.

11. Kretapirom K, Okochi K, Nakamura S, Tetsumura A, Ohbayashi N, Yoshino N, Kurabayashi T. (2013): MRI characteristics of rheumatoid arthritis in the temporomandibular joint. Dento maxillofac radiol., 42 (4).

12. Levin RW, Park J, Ostrov B, Reginato A, Baker DG, Bomalaski JS, et al. (1996):Clinical assessment of the 1987 American College of Rheumatology criteria for rheumatoid arthritis. Scand J Rheumatol., 25: 277281.

13. Okochi K, Kretapirom K, Sumi Y, Kurabayashi T. (2011): Longitudinal MRI follow-up of rheumatoid arthritis in the temporomandibular joint: importance of synovial proliferation as an early-stage sign. Oral Radiol., 27: 83 86.

14. Rindfleisch JA and Muller D. (2005): Diagnosis and Management of Rheumatoid Arthritis. Am Fam Physician, 72 (6): $1037-1047$.

15. Schellhas KP, Piper MA, Omlie MR. (1990): Facial Skeleton Remodeling Due to Temporomandibular Joint Degeneration: An Imaging Study of 100 Patients. AJNR., 11: 541 - 551.

16. Smith HJ, Larheim TA, Aspestrand F. (1992): Rheumatic and nonrheumatic disease in the temporomandibular joint: gadolinium-enhanced MR imaging. Radiology, 185: 229 - 234.

17. Sommer OJ, Aigner F, Rudisch A, Gruber H, Fritsch H, Millesi W, Stiskal M. (2003): Cross-sectional and functional imaging of the temporomandibular joint: radiology, pathology, and basic biomechanics of the jaw. Radiographics, 23: e14.

18. Syrjanen SM. (1985): the Temporomandibular joint in rheumatoid arthritis. Acta Radiol Dia., 26:235-243.

19. Tsiklakis K. (2010): Cone beam computed tomographic findings in temporomandibular joint disorders. Alpha Omegan, 103 (2): $68-78$.

20. Uchiyama Y, Murakami S, Furukawa S. (2013): Temporomandibular joints in patients with rheumatoid arthritis using magnetic resonance imaging.Clin Rheumatol., 32 (11): $1613-8$.

21. Weishupt D, Kochli VD, Marinccek B. (2006): How Does MRI work? An introduction to physics and function of MRI. 2nd ed. Springer, 1- 47.

22. Westesson PL, Brooks SL. (1992): Temporomandibular joint: relationship between MR evidence of effusion and the presence of pain and disk displacement. AJR Am J Roentgenol., 159: 559 - 563.

23. White SC, Pharoah MJ. (2014): Oral Radiology principles and interpretation. 7th ed. Mosby.

24. Witulski S, Vogl TJ, Rehart S, Ottl P. (2014): Evaluation of the TMJ by means of Clinical TMD Examination and MRI Diagnostics in Patients with Rheumatoid Arthritis. Biomed Res Int.

25. Yilmaz HH, Yildirim D, Ugan Y, Tunc SE, Ahmet Yesildag A, Orhan H, et al. (2012): Clinical and magnetic resonance imaging findings of the temporomandibular joint and masticatory muscles in patients with rheumatoid arthritis. Rheumatol Int., 32:1171 - 1178. 